\title{
Economic Inequality in the Access to Remote Learning Assets Amongst Youth in BRICS Countries: What Can We Learn from Pre-COVID-19 Data?
}

\section{Garen Avanesian $^{1}$, Marina Borovskaya ${ }^{2}$, Sakshi Mishra ${ }^{3}$, Marina Masych ${ }^{4}$, Tatiana Fedosova ${ }^{5}$, Valeria Egorova ${ }^{6}$}

1 Southern Federal University,

105/42, Bolshaya Sadovaya Str., Rostov-on-Don, 344006, Russian Federation.

E-mail: avanesian@sfedu.ru

2 Southern Federal University,

105/42, Bolshaya Sadovaya Str., Rostov-on-Don, 344006, Russian Federation. E-mail: bma@sfedu.ru

${ }^{3}$ Columbia University, New York, USA.

E-mail: sm4557@columbia.edu

4 Southern Federal University,

105/42, Bolshaya Sadovaya Str., Rostov-on-Don, 344006, Russian Federation.

E-mail: mamasych@sfedu.ru

5 Southern Federal University,

105/42, Bolshaya Sadovaya Str., Rostov-on-Don, 344006, Russian Federation.

E-mail: tvfedosova@sfedu.ru

${ }^{6}$ Southern Federal University,

105/42, Bolshaya Sadovaya Str., Rostov-on-Don, 344006, Russian Federation.

E-mail: veremeeva@sfedu.ru

This paper analyzes economic inequalities in the access to such assets for remote learning as internet connection and personal computers at home in BRICS countries among young students (15-24 years old). It is acknowledged that such household possessions as the internet and personal computer obtain a new role during the COVID-19 pandemic when the educational institutions are closed and

Garen Avanesian - Senior Researcher.

Marina Borovskaya - Professor of Economics.

Sakshi Mishra - Master in Public Administration (MPA).

Marina Masych - Associate Professor of Economics.

Tatiana Fedosova - Associate Professor of Economics.

Valeria Egorova - Master student.

The article was received: 07.07.2021/The article is accepted for publication: 16.09.2021. 
in-person classroom instruction is disrupted. Data from household surveys collected from 2015 to 2019 show sharp differences between and within BRICS countries regarding access to these assets for remote learning. In addition to betweencountry inequalities, the analysis suggests that within-country disparities are also staggering, especially regarding an area of residence and wealth quintile groups, putting at risk the education of youth from most impoverished and rural backgrounds. Econometric application of concentration curves and estimation of concentration indices reveals household wealth as an essential driver of economic inequality in the access to remote learning amongst young students in BRICS countries, highlighting the critical degree of inequality in India and South Africa. The findings suggest that the more universal the access to remote learning is, the less economic inequality is observed in accessing remote learning modalities. In other words, policy implications aimed at expanding digital infrastructure could help ensure that young women and men are not falling behind in receiving a quality education, gaining relevant skills, and accessing decent employment opportunities. For BRICS countries to transform their economies and lead innovations, a digitally literate future workforce is critical, with access to digital resources being a first step towards achieving this. Inequalities in access to these tools show that BRICS countries have more to do before all youth can be connected and participate in a digital economy.

Key words: COVID-19; educational inequality; educational equity; remote learning; internet access; household possessions; concentration curves; concentration indices.

JEL Classification: I24, I25, I28, D31, D63, C13.

DOI: $10.17323 / 1813-8691-2021-25-3-359-378$

For citation: Avanesian G., Borovskaya M., Mishra S., Masych M., Fedosova T., Egorova V. Economic Inequality in the Access to Remote Learning Assets Amongst Youth in BRICS Countries: What Can We Learn from Pre-COVID-19 Data? HSE Economic Journal. 2021; 25(3): 359-378.

\section{Introduction}

BRICS refers to the group of 5 countries (Brazil, Russia, India, China and South Africa) that make up to $40 \%$ of the world's population and in 2019 contributed to 33 per cent of the global GDP, an estimate that IMF believes will increase to be 50 percent of the global GDP [Larionova, 2020]. The countries are grouped together because of their growth potential i.e., the growth rate in each of the BRICS countries is higher than the global growth rate. Despite their immense growth potential, inequality remains a key challenge in the BRICS countries. The Gini coefficient ranges from 0.634 in South Africa to 0.357 in India indicating the extent to which the richest population disproportionately benefits from income in these countries ${ }^{1}$. Public infrastructure and

\footnotetext{
1 Data using Gini coefficient (World Bank estimate). The most recent year for the country differs, these are Brazil (0.534 in 2019); Russia (0.375 in 2018); India (0.357 in 2011); China (0.375 in 2016) and South Africa (0.630 in 2014).
} 
services continue to be a challenge in BRICS countries with the poorest bearing the most severe consequences of existing inequalities. COVID-19 pandemic has added strain to an already weak socio-economic structure of sharpened inequalities. Due to the large population size, India, Brazil, and Russia are among the top five countries with the highest number of COVID-19 infections. For education systems in the BRICS countries, COVID-19 pandemic has resulted in the closure of educational institutions and deployment of the remote learning policies by the ministries of education.

Consequently, children and young people who represent the future workforce have been negatively impacted due to school closures in a highly unequal setting in these countries. India and China are among the largest education system in the world and across BRICS, based on most recently available data, primary school enrolment is over 85 percent [UNESCO, 2014; World Bank, 2021]. Among the BRICS countries, schools were closed for 65 days in Russia to 235 days in India [UNICEF, 2021a]. With infections continuing, full and nation-wide return to in-person classroom setting may not be possible for a long time. BRICS countries responded to school closures with remote learning solutions ranging from providing lessons through TV, radio, digital platforms (such as computers, laptops, tablets and smartphones) and in some cases delivery of paper-based material to children in their homes.

In response to the pandemic, the governments dosed the schools across BRICS countries in March 2020. But given the vastness of BRICS countries, response within a country differed by location. For example in Brazil, some states broadcasted educational content on open television via satellite, along with social media livestreaming and applications [World Bank, 2020]. For higher education, in Brazil some universities allowed students to convert their studies to internships during the period of the pandemic. In Russia, there was a universal shift to online learning for all three levels of basic education. More than 200 Russian universities also moved to online learning in March 2020. In September 2020 with school and universities re-opening, some continued to opt for hybrid learning (some in-person days and some remote learning days). India closed all educational institutions as part of its lockdown and the government launched many initiatives to facilitate remote learning. These include DIKSHA which made available ebooks for grades 1 to 12 , e-PATHSHALA and National Repository of Open Educational Resources, an online learning platform providing materials in different languages for grade 1 to 12 . Similar initiatives were also launched for higher education, with all these resources being made available at no cost. China was the first country to close schools due to COVID-19 and moved to digital platforms for teaching and lear-ning [Niemczyk et al., 2021]. However, decision making on the mode of delivery was local, which included choice between online platform, televised learning or use of mobile applications. In South Africa, while TV or paper-based learning were the choice of remote learning modality for primary and secondary students, online platforms were the choice for higher education.

However, available studies suggest that the effective coverage of remote learning policies could be limited due to two key factors which refer to the inequitable access to the ICT at home and capacity of a country's policy response [UNICEF, 2020; Avanesian et al., 2021]. Among the governmentally deployed solutions, digital learning platforms have the strongest possibility of emulating classroom-type setting. They enable interactive learning and allow teachers to track students' progress in real time [UNICEF, 2021]. All BRICS countries adopted remote learning through the digital channels [UNESCO, UNICEF, The World Bank, 2020]. However, access to this type of learning depends on the availability of computers and the quality high-speed internet connection at home, which is more costly in comparison to broadcast assets such as radio or TV. 
Access to Information and communication technology (ICT) and possession of digital skills were already at the center of the global development agenda in the pre-pandemic era due to its importance in the increasingly digitalized world. The Sustainable Development Goals (SDGs) 2030 highlight this with, both, SDG4 on achieving quality education and SDG9 on building resilient industry, innovation having a strong focus on access to ICT and developing ICT skills. With these regards, available evidence emphasizes the need to equip youth with digital skills to ensure ease of getting jobs or starting a business [ITU, 2014]. The high rates of the share of youth not in education, employment, or training (NEET) in the BRICS countries indicate that many young people are not able to utilize their potential. Among BRICS with available data, the share of NEET is highest for South Africa at 32.5, followed by India 29.5, Brazil 23.5, and Russia 12.5 [World Bank, 2021]. The pandemic could have a long-lasting impact on the high-skilled workforce as inequalities in the access to remote learning dramatically exacerbate learning loss [Azevedo et al., 2020]. In other words, the progress toward reaching the objectives of SDG4 on quality equitable education and SDG8 on decent work and economic growth could be undone, throwing BRICS economies back in their social and economic development. Available evidence suggests that generation of students whose learning was disrupted will experience an estimated drop in earnings on average equal to approximately $\$ 820$ per year [Ibid, 2020], and the most affected countries will move forward experiencing deficit in the qualified workforce thus loosing on their national welfare [Hanushek, Woesmann, 2020]. Negative socio-economic consequences of COVID-19-caused school closures could be devastating if educational systems would not be able to reach the level of indicators shown in 2019 [Ibid, 2020].

This study seeks to address this gap and focuses on assessment of the first-order effects of the digital divide, a term used to define inequalities in the access to ICT [van Deursen, van Dijk, 2019; Ragnedda, Ruiu, 2020]. As opposed to first-order effects, second-order effects are related to the actual use of digital devices in everyday life [Purushothaman et al., 2017]. Their analysis goes beyond the scope of this paper. Since BRICS countries represent a group of developing economies, they "generally lag in terms of the maturity of physical digital infrastructure (access speed, number of active users and households with Internet access)" [Ignatov, 2020]. Therefore, focusing on the first-order effects of the digital divide in remote learning assets is essential as access to the digital world is far from being universal. Furthermore, the existing research outlines that both education and ICT use have a positive impact on alleviating poverty in BRICS countries [Tsaurai, Chimbo, 2020]. Overcoming the first-order effects of the digital divide is necessary for the economies to move forward, as access to the ICT is the basic, but not the only dimension of the inequalities in the increasingly digitalized societies. With these regards, BRICS countries demonstrate inequalities both within and between, as each of them has different stand in the development of digital infrastructure, ranging from $15 \%$ of households connected to internet in India to 70\% in Russia [Baller et al., 2016]. However, the conceptual framework of the study should be focused not on investigating the access per se, but how the access relates to the social issues in terms of a risks of inequality or exclusion [Brotcorne et al., 2010] that schoolchildren in BRICS countries are expected to due to the COVID-19 pandemic.

As such, quantifying the share of children and young people with necessary ICT at home helps understand if they could access education during the COVID-19 pandemic. Prior research on first-order effects identified differences in family income and parental education as key factors predicting differences in internet access [Livingstone et al., 2005; Bonfadelli, 2002]. With these regards, the study's central research question is to estimate the degree of economic ine- 
quality in the access to remote learning tools such as internet and personal computer. Adopting this logic, the study is guided by the following research questions:

- What is the prevalence of such assets for remote learning as internet connection and computer at the household level amongst young students in BRICS countries?

- How much the disparities observed in the possession of the assets for remote learning are driven by the area of residence and wealth rank?

- To what extent the inequalities in the access to the assets for remote learning are concentrated in the accumulated household wealth?

Given the unique circumstances imposed by COVID-19, no studies using nationally representative data have been undertaken to understand youth's access to ICT during COVID-19 and its impact on their education. This is because nationally representative data of remote learning coverage during the pandemic have either not yet been captured or are not readily available. So far, evidence on ICT access during COVID-19 has been based on ad-hoc responses of ministry officials, surveys restricted to certain geographical location or estimations/simulations made by ministries and researchers [UNESCO, UNICEF, The World Bank, 2020]. Moreover, as school closures lasted for a longer period than countries initially expected, governments also responded with expanding remote learning through different solutions given that some children were not reached by national policy options. These changes make it difficult to estimate how many children were truly reached by remote learning policies. However, given that of all remote learning tools digital solutions are best able to emulate classroom setting, this paper focuses on ICT access using the most recent national representative data. In doing so, this research captures access to ICT towards the beginning of the pandemic i.e. before government intervention to expand access, if any.

\section{Methods and Data}

For producing the analysis presented in the study, the data from national and international household surveys from all BRICS countries were used. Each country is represented by the latest available data source starting from the year 2017 onwards, which ensures that the analysis reflects the most recent available household survey data. The surveys used were carried mostly by the national statistical offices as a part of national monitoring. Therefore, a major challenge referred to the data standardization. However, it was ensured that all the datasets have a minimum set of variables necessary to carry out the analysis. These key variables refer to internet access at home, PC at home, area of residence (urban/rural), and wealth by quintile group. For producing the estimates, we tried to exclude the mobile networks to the possible extent. As such, in Brazil, we looked at access to the internet through a computer, in Russia, the variable was defined as high-speed internet. In China and South Africa, it was a fixed internet connection ${ }^{2}$. Despite the codebook for India says that internet variable also accounts for

\footnotetext{
2 While the question in the Indian Demographic and Health Survey does not specify the type of internet connection at home, the codebook suggests that it includes mobile networks. However, descriptive analysis of data and survey findings report suggests that the estimated number of households with the internet is very far from the share of households with the mobile phone, but almost equal to those with computer possessions. It allows for hypothesizing that the question could be misunderstood, and, in fact, the respondents report fixed or high-speed connection.
} 
the mobile networks, the number is quite different from the possession of mobile phones. Therefore, the Indian estimates for the internet are supported by the data on computer possession which shows a similar prevalence. The presence of a household roster in each dataset allowed to select of the subsamples of respondents in the age of 15-24 years and exclude out of this cohort those who are not attending educational institutions. In other words, the figures presented in the study refer to the young students.

For the carried-out research, we used five datasets, each providing a representative sample of the country. The parameters of the sample are presented in Table 1.

Table 1.

\section{Summary statistics of the sample}

\begin{tabular}{l|c|c|c|c|c}
\hline \multirow{2}{*}{ Country } & \multicolumn{2}{|c|}{ Sex } & \multicolumn{2}{c|}{ Area } & \multirow{2}{*}{ N } \\
\cline { 2 - 5 } & Female & Male & Rural & Urban & \\
\hline Brazil & $50 \%$ & $50 \%$ & $13 \%$ & $87 \%$ & 35,067 \\
China & $47 \%$ & $53 \%$ & $69 \%$ & $31 \%$ & 987 \\
India & $46 \%$ & $54 \%$ & $66 \%$ & $34 \%$ & 161,420 \\
Russia & $56 \%$ & $44 \%$ & $30 \%$ & $70 \%$ & 1,191 \\
South Africa & $49 \%$ & $51 \%$ & $59 \%$ & $39 \%$ & 6,409 \\
\hline \hline
\end{tabular}

Source: Authors' calculations based on the household survey data (2015-2019).

As the purpose of the analysis is not limited to country-level inferences only but aims at understanding general state of inequities in the access to the quality remote learning in BRICS countries, aggregated estimates were produced using population weighted averages, i.e., each country was weighted by the number of population in the age 15-24 years old.

Based on the descriptive statistics on availability of the household assets for remote learning broken down by key population subgroups, we calculated parity ratios. Parity ratios are introduced as a part of SDG4.5.1, and normally they are produced with regards to access to education in terms of attendance and enrolment. In this study, we used a similar approach to estimate disparities in the access to remote learning assets. They are calculated using the equation below:

$$
P R_{g_{1} / g_{2}}=\frac{P_{g_{1}}}{P_{g_{2}}} .
$$

Where $P_{g_{1}}$ is the share of youth population in group $g_{1}$ with access to a certain asset, $P_{g_{2}}$ is the share of population in group $g_{2}$ with the same asset, and $P R_{g_{1} / g_{2}}$ is a parity ratio between the groups. Normally, $g_{1}$ tends to be a vulnerable group put in the numerator, whereas supposed dominant group $g_{2}$ is put in the denominator. With these regards, the received ratio would indicate by how many times the possession in the dominant group is higher than in the vulnerable group. 
For estimating the degree of inequalities in the access to household assets needed for a quality remote learning, we calculated concentration indices for each asset per country to see to what extent it is concentrated in economic hierarchy of the society. Plotting of the concentration curves corresponding to these concentration indices provided visual representation of the degree of inequality. As such, the curve shows a share of the outcome variable (availability of ICT at home) possessed by a certain fraction of the households sorted by wealth/income in the ascending order. The cumulative proportion of the population with household assets for remote learning is ordered from the lowest to highest and plotted on the y-axis against the cumulative proportion of the youth population, ranked by wealth, from the poorest to the richest on the x-axis.

In other words, concentration curves are bivariate versions of the Lorenz curve: while Lorenz curves assess inequality when the variable of outcome is ranked in own terms, concentration curve examines how certain outcome is concentrated in income, wealth, or another proxy of wealth. Like with the Lorenz curve, it is possible to derive index that expresses the degree of inequality. Concentration index derived from the concentration curve has the same logic as Gini coefficient. It quantifies economic inequality in education and is defined as twice the area between the concentration curve L(s) and egalitarian line. The equation suggested by [Kakwani, 1977] is used in this paper:

$$
C_{h y}=1-2 \int_{0}^{1} L(s) d s .
$$

In this paper, we used computational algorithms suggested by R package IC2 dedicated specifically to the inequality and concentration analysis [Platt, 2012], which adopts calculation of concentration curves and indices based on [Kakwani, 1977]

The concentration index derived from the curve varies in the interval from -1 to 1 , with the extreme values indicating a higher economic inequality in the distribution of the remote learning asset. The values closer to 0 tend to coincide with the egalitarian line and express low inequality, whereas negative and positive values express concentration of the asset either amongst poor or rich respectively. The method of concentration curves has been widely used in health economics, and computational detail behind the approach could be found in [Kakwani, Wagstaff, van Doorslaer, 1997; Van Doorslaer et al., 1997; Wagstaff, Paci, van Doorslaer, 1991; Regidor, 2004; Illsley, Le Grand, 1897; Wagstaff, van Doorslaer, 1994; Erreygers, Van Ourti, 2011]. While playing important role in estimating the inequalities in health, there was a limited application of concentration indices to the educational outcomes. However, concentration curves fit well if one seeks to understand to what extent inequalities observed in the statistical distribution of a certain educational outcome (access to quality remote learning in the case of this paper) are shaped by the economic structure of society. In other words, by analyzing inequality they also shed light on equity of education and learning by assessing how equal is distribution of an asset across the sorted by wealth population.

\section{Research Limitations}

The study has several limitations due to the data constraints. First, though the analysis covers all BRICS countries, and all key variables are present, the surveys belong to different na- 
tional programs instead of representing one standardized cross-country assessment. This has clear implications on how the variables are defined and the broad set of variables included in the analysis. For example, the countries could have different approaches in defining internet access by their national classifications while collecting the data from households. Second, different variables were used as a proxy of household wealth. While some countries like Brazil, Russia, and South Africa have household income variables, China and India rely on the wealth index derived from household possessions. We used the relative rank of a household divided by wealth quintile groups to make the data comparable. Third, due to the lack of data, Chinese analysis does not include computer possession, making it impossible to estimate the overlap between two distributions for the group of young Chinese students. Moreover, the sample size for China is relatively smaller than for other countries, presenting a subset of the 15-24 student population from the nationally representative household survey.

Finally, the availability of internet and PC at household does not mean that a student is learning, as many obstacles for accessing remote learning could be in place. However, the purpose of the analysis is not to quantify the share of those who are learning. On the opposite, it is to estimate the share of a vulnerable group of those young people who cannot access education due to the inequalities in possession to certain household assets.

When it comes to the availability of the variables for analysis, there could be some other predictors of inequalities in the access to remote learning assets that go beyond wealth and area of residence, such as parental education, parental occupation, personal employment status, and others. However, because these data being available for some countries are not present for others, this comparative cross-national study cannot produce meaningful inferences regarding the effects mentioned above for all BRICS countries. Considering this, a deeper understanding of the inequality drivers in a country-specific context could be a direction for future research.

\section{Results}

\subsection{Prevalence of remote learning assets}

Inequalities in access to such household assets for remote learning as computer and internet are explicit within and between the BRICS countries. Young students in Brazil, China and Russia demonstrate a higher prevalence of fixed internet connection at home, reaching more than $60 \%$. On the other side, critical situation is observed in India and South Africa where only smaller proportions of student youth can access internet from home $14.8 \%$ and $8.5 \%$ respectively). All in all, it results in a weighted average of $36.6 \%$ of student youth across BRICS countries who can access internet from home. Furthermore, the discrepancies are observed between the internet access and computer possessions, suggesting that two distributions have limited overlap. While in Brazil and India share of young population of students with internet access at home dominates over those who possess computer, the reverse pattern is observed in South Africa and Russia, where more young students have computer at home than fixed internet connection. The difference in numbers can potentially be explained by the lack of digital infrastructure in some areas, i.e., when household wealth allows for purchasing computer, but location of a household does not allow for accessible fixed internet connection. A deeper, countryfocused investigation is needed though to prove this thesis fully. The data on availability of the assets for remote learning are present on Fig. 1. 


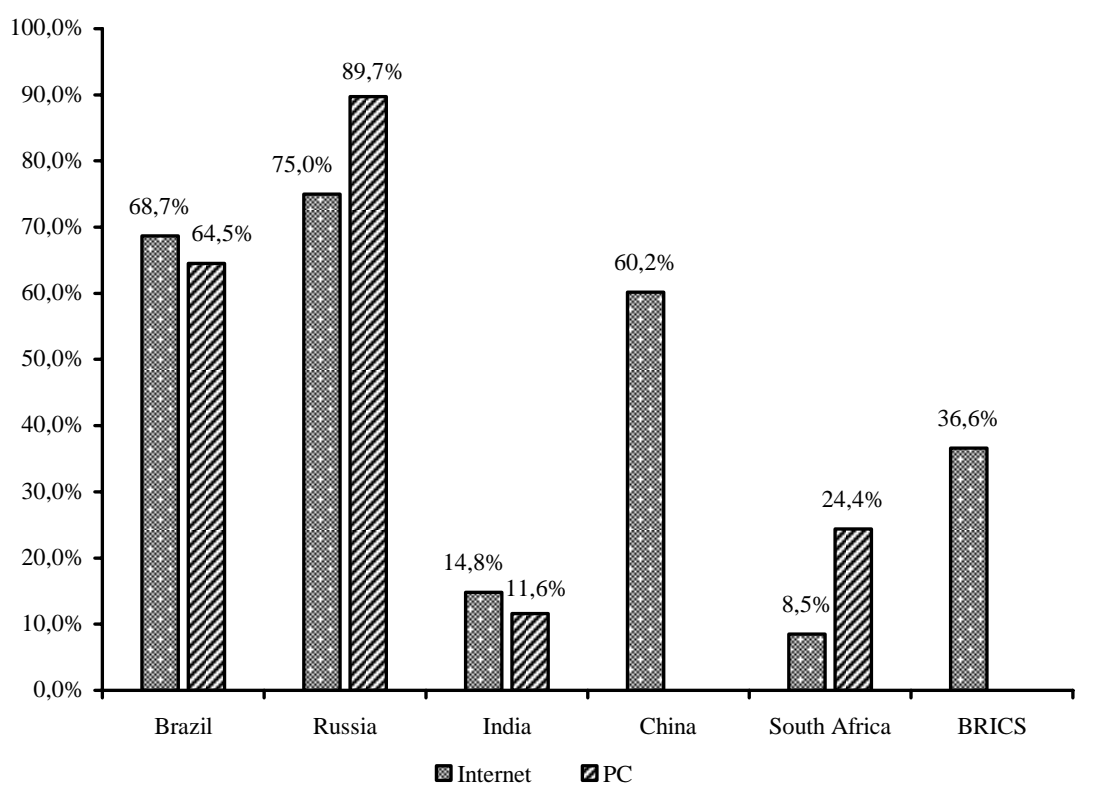

Fig. 1. Access to internet from home and computer possession amongst student youth (15-24 y. o.) in BRICS countries, \%

Source: Authors' calculations based on the household survey data (2015-2019).

\subsection{Socio-economic disparities}

Within-country inequalities become evident when one disaggregates country averages by area of residence and household wealth. All countries demonstrate substantial disparities in access to digital infrastructure between rural and urban areas. The largest disparities are in Brazil where more than $70 \%$ of urban student youth has internet access at home in opposition to only $36.2 \%$ of rural student youth. India and South Africa also show differences in access that favor urban youth. Given that access to internet and PC is low nationally in India and South Africa, the differences between urban and rural become more important as they clearly highlight the advantage that urban youth. Amongst BRICS, disparities in access to internet between rural and urban infrastructure being explicitly pronounced in China and Russia, appear to be less critical as at least half of the rural youth population can go online using a fixed connection. All in all, while $48.9 \%$ of urban student youth in BRICS countries has access to internet from home, only $27 \%$ of rural does. Similar inequality patterns apply to the possession of computers at home, highlighting not only lack of infrastructure in remote areas but also additional factors that result in the lack of computer possessions. Disaggregation of internet access and computer possession by area of residence is presented on Fig. 2 . 


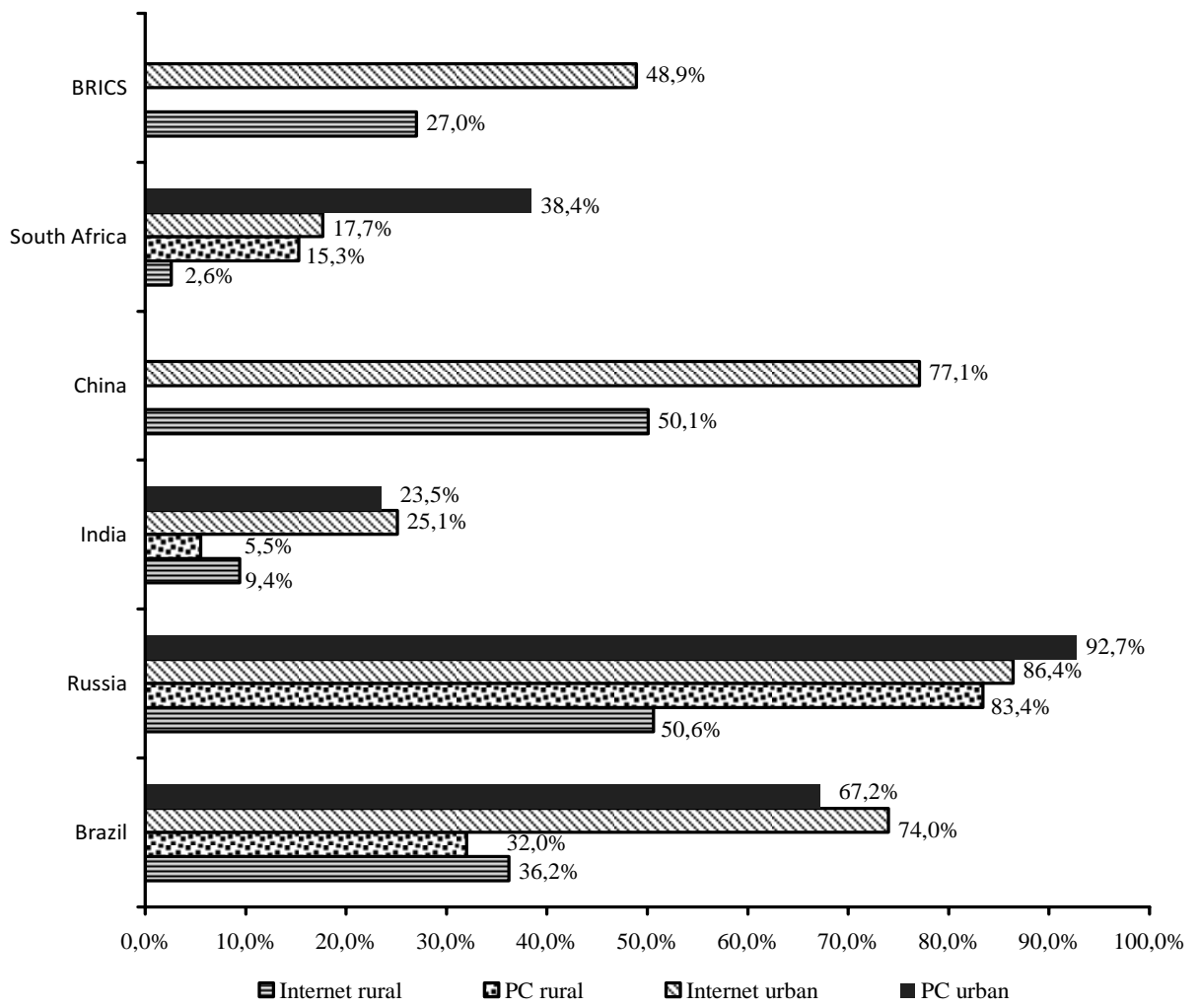

Fig. 2. Access to internet from home and computer possession amongst student youth (15-24 y. o.) in BRICS countries broken down by area of residence, \%

Source: Authors' calculations based on the household survey data (2015-2019).

Economic status appears to be another dimension that drives inequalities in access to quality remote learning, putting the poorest young students under the substantial risks of falling behind in their education. In Brazil, China, and Russia, where access to internet amongst student youth tends to be relatively high, the availability of internet connection at home amongst richest quintiles is at least $85 \%$. However, even in these countries, groups of the poorest student youth are disadvantaged in access internet at home. The most dramatic disparities between the student youth from the poorest and richest families is found in India, where in opposition to $43.6 \%$ of the richest ones only $0.9 \%$ of the poorest ones can access internet from home. In other words, access to internet amongst the poorest young students in this country is almost non-existent, which highlights educational emergency for the skills and gains of this cohort in future. Not surprisingly, the possession of computer across all BRICS countries demonstrates similar inequities, thus exacerbating the vulnerability of the poorest young students in their access to the quailty remote learning. The data on access to internet and possession of computers broken down by wealth are present on Fig. 3. 


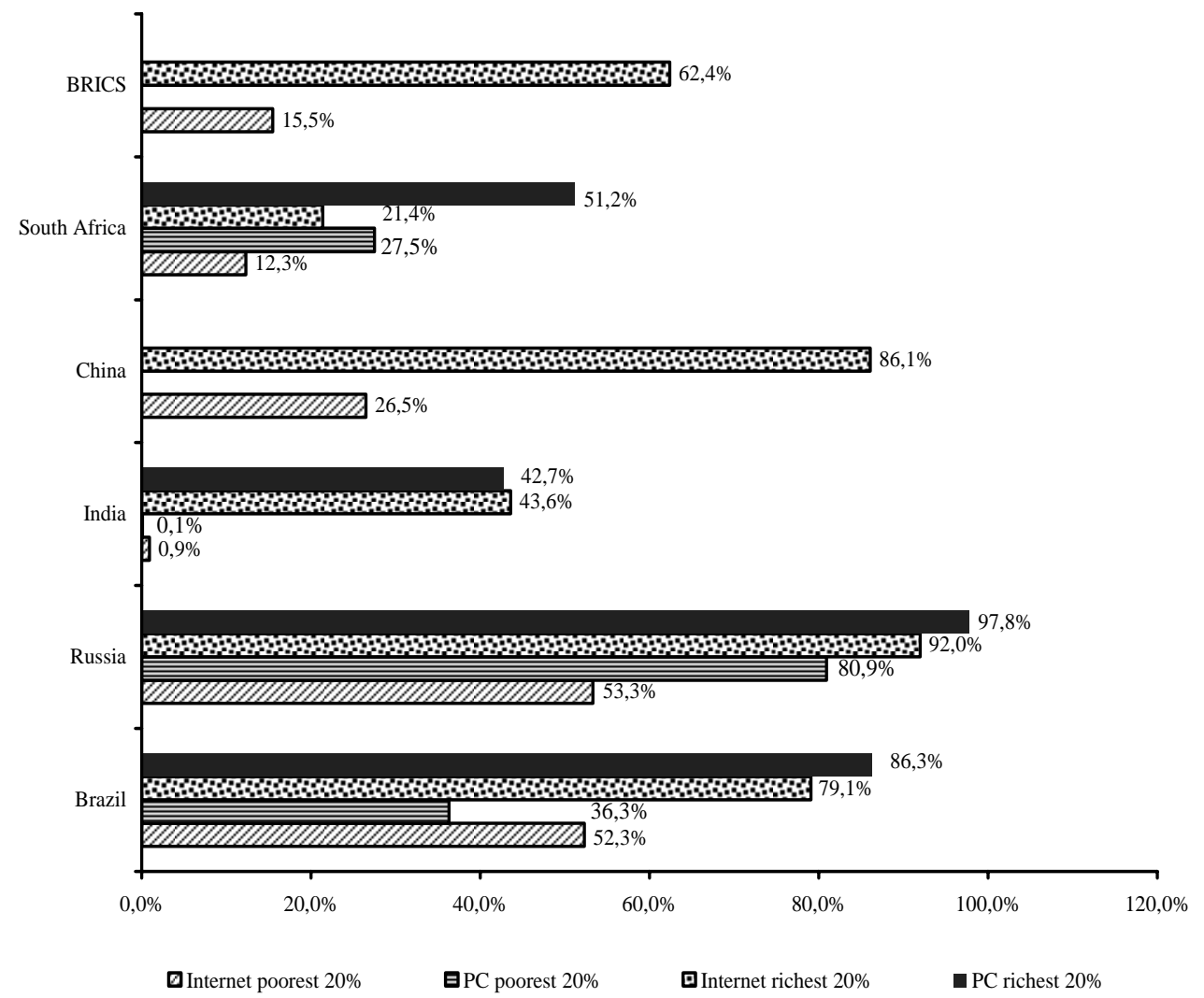

Fig. 3. Access to internet from home and computer possession amongst student youth (15-24 y. o.) in BRICS countries broken down by wealth, \%

Source: Authors' calculations based on the household survey data (2015-2019).

The calculated values on prevalence allow for estimating the degree of socio-economic disparity between the groups of student youth population by area of residence and wealth. As such, within the SDG framework none of the countries reaches parity in terms of rural/urban and poorest/richest oppositions both in light of internet access and computer possession, as all of the calculated parity ratios do not fall in the range between 0.97 and 1.03 . With these regards, values closer to 0 would indicate the higher vulnerability of the group in numerator (rural or poorest youth respectively), whereas values above 1 theoretically mean that the groups in numerator possess more of a certain asset. The lowest parity in internet connectivity by rural/urban is in South Africa, where for every 100 urban youth connected with internet only 15 rural youth are connected. Parity ratios of the poorest and richest youth in India reveal an extremely low ratio. For every 100 richest youth in India with internet at home, only 2 poorest youth have internet at home. Economic lines are present in access to computer at home in India with not even one poor young student having access to computer at home for every 100 rich Indian. Being devastating, the disparities in wealth highlight the urgent need for policy action aimed to 
enable access to the digital world among the poorest student youth in BRICS countries. The data on parity ratios by country are presented in Table 2 .

Table 2.

Parity ratios for internet access and computer possession amongst student youth (15-24 y. o.) in BRICS countries by area of residence and wealth

\begin{tabular}{l|cc|c|c}
\hline \multirow{2}{*}{ Country } & \multicolumn{2}{|c|}{ Internet connection } & \multicolumn{2}{c}{ Computer } \\
\cline { 2 - 5 } & Rural/Urban & Poorest/Richest & Rural/Urban & Poorest/Richest \\
\hline Brazil & 0.49 & 0.66 & 0.48 & 0.42 \\
China & 0.65 & 0.31 & - & - \\
India & 0.37 & 0.02 & 0.23 & 0.02 \\
Russia & 0.59 & 0.58 & 0.87 & 0.82 \\
South Africa & 0.15 & 0.51 & 0.40 & 0.54 \\
BRICS & 0.55 & 0.25 & - & - \\
\hline \hline
\end{tabular}

Source: Authors' calculations based on the household survey data (2015-2019).

\subsection{Concentration analysis}

The analysis above presents a concerning picture of the inequitable access to digital tools by young students in BRICS countries. However, the primary question regarding the degree of inequality yet remains unaddressed. The calculated estimates suggest that wealth is the key driver of inequality in the statistical distribution of household assets needed to access quality remote learning. First, however, it is essential to understand the inequality in digital connectivity and digital devices in each of the BRICS countries. In this context, the concentration analysis aims not to understand how to redistribute access to the internet and computer possession from rich to the poor or vice versa but rather to compare the distribution of access to these tools against wealth ranking within BRICS countries.

The country-specific plots on Fig. 4 across all BRICS countries lie below the egalitarian line (45-degree line), suggesting that the distribution amongst the richer youth drives the inequalities in access to remote learning assets. In other words, the rich ones possess the higher shares of digital tools needed to access remote learning through digital channels. The corresponding values of concentration indices presented in Table 3 are also positive, indicating economic inequality in access to remote learning. Economic inequalities in internet access and computer possessions are not strongly pronounced in Russia and Brazil, where the respective concentration curves approximate the egalitarian line. On the other hand, South Africa and India show high levels of economic inequality for both assets, implying that in these countries, access to remote learning is in many ways a function of the household's wealth. China appears to be in the in-between position; with a relatively high prevalence of fixed internet access at home amongst young students, it also shows higher concentration amongst well-off youth, highlighting that the poorer ones could have limited access to the remote learning opportunities. Thus, the most definitive conclusion regarding countries with the higher shares of the young population possessing assets for remote learning is that they also demonstrate low economic inequality. In 
other words, the more universal becomes the access to digital world, the less is level of economic inequality in the access to remote learning opportunities.
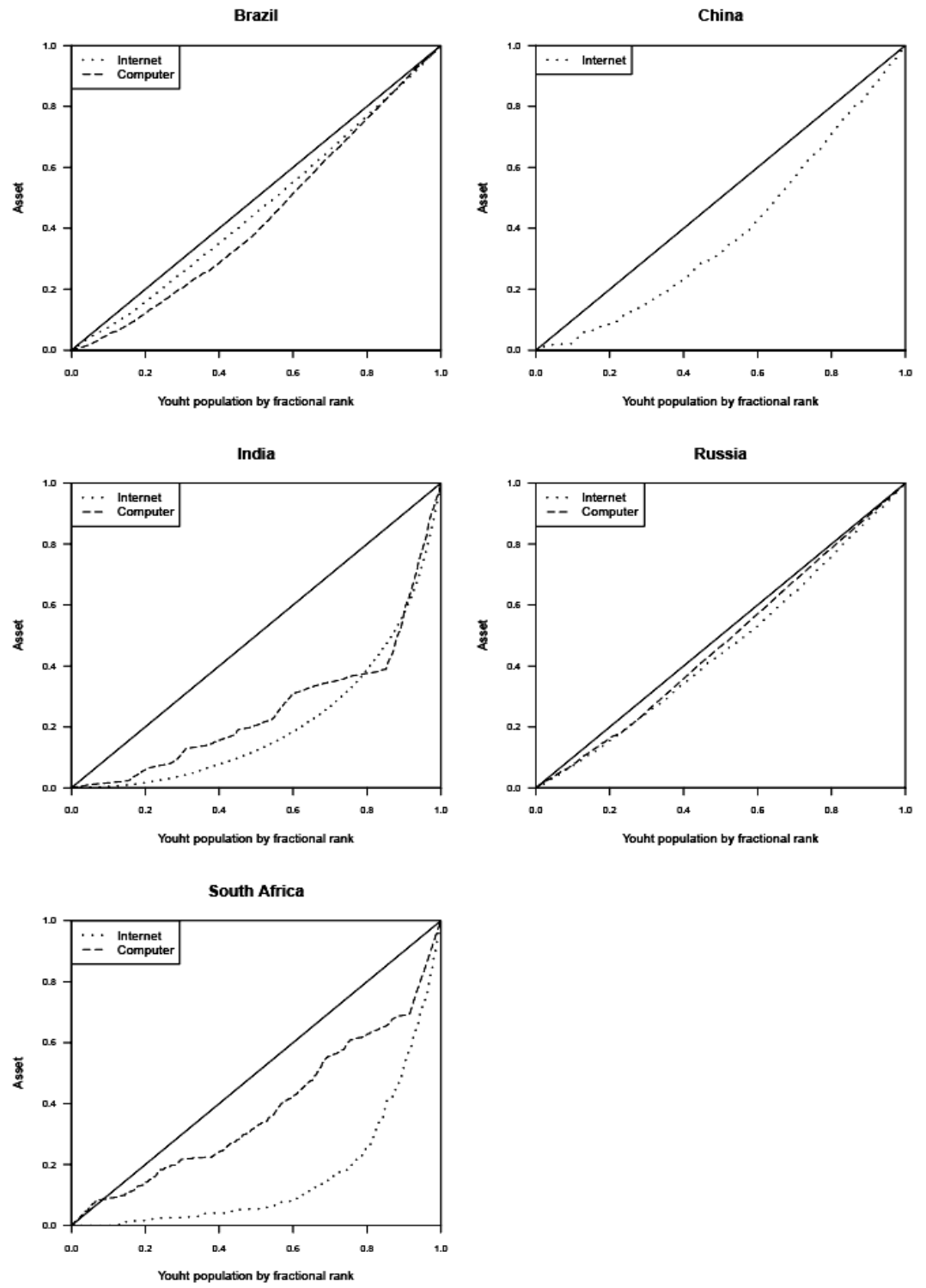

Fig. 4. Concentration curves of internet access and computer possession amongst young students (15-24 y. o.) in BRICS countries

Source: Authors' calculations based on the household survey data (2015-2019). 
Typically, the shape of the concentration curve serves as the means of statistical inference regarding the elasticity of a specific commodity with relation to income, highlighting positive (negative) elasticities in cases when the curve is concave (convex) towards the origin coordinates [Yitzhaki, Slemrod, 1987]. However, in these cases, the concentration curves should take income as a ranking variable and expenditure on a specific asset as the output variable, which is not the case for this research. Nonetheless, comparing two concentration curves in relation to each other allows for producing inferences regarding the welfare dominance in possession of a specific asset. It was suggested that "if the concentration curve of one commodity is above the concentration curve of another commodity, then the first commodity dominates the second. However, if the concentration curves intersect, then it is impossible to show dominance. In other words, only if concentration curves do not intersect will all social welfare functions show that" distributional changes can increase welfare. Conversation on the distributional changes in the context of the remote learning assets should not be taken as a proposal to take the assets from reach and give them to the poor, but to reinforce the state policy on the expansion of digital tools amongst the youth population. The dominance is observed in all countries except for India, where curves for computer and the internet being strongly concave toward the origin also intersect. In other words, it is impossible to conclude that one economic inequality dominates another. Brazil appears to be a country where economic inequality in the distribution of computer possession dominates over the inequality in access to the internet. The opposite pattern is observed in Russia and South Africa, where economic inequalities in access to fixed internet connection dominate those in computer possession. As such, the South African case appears to be the most distinct as both curves are concave. However, the difference between them identifies the critical gap in the availability of both assets in one household. It can be hypothesized that higher shares of the young population possess computers than have internet access from home due to the lack of digital infrastructure or unaffordable internet prices in South Africa. The available evidence suggests that South Africa tops BRICS countries in this aspect [Broadband Search, 2021], which identifies an area of policy action in democratizing the prices for internet data.

Table 3.

Concentration Indices for internet access and computer possession amongst student youth (15-24 y. o.) in BRICS countries

\begin{tabular}{l|c|c}
\hline Country & $\begin{array}{c}\text { Concentration Index } \\
\text { (Internet access) }\end{array}$ & $\begin{array}{c}\text { Concentration Index } \\
\text { (Computer possessions) }\end{array}$ \\
\hline Brazil & 0.071 & 0.139 \\
Russia & 0.088 & 0.037 \\
India & 0.577 & 0.722 \\
China & 0.224 & \\
South Africa & 0.679 & 0.415 \\
\hline \hline
\end{tabular}

Source: Authors' calculations based on the household survey data (2015-2019). 


\section{Discussion}

The data analyzed in this study explicitly outline that access to digital tools among youth in BRICS countries is associated with socio-economic realities, with poorer youth being at higher risk of exclusion from receiving quality education during closures of educational institutions. Realities of inequitable education become more amplified during the pandemic. Moreover, access to ICT is the first step to build a digital economy, and the evidence in the paper suggests that BRICS countries need to invest much more to achieve this. Indeed, each of the BRICS countries has launched initiatives to digitize their economy: India has the "Digital India" initiative, while China has "Digital China," and Russia has the 'Digital Economy of Russian Federation' approved in 2017, Brazil has the 'Brazilian Digital Transformation Strategy,' and South Africa has 'South Africa connect' [Digital India, 2021; Deng, Shen, 2021; OECD, 2018; Department of Communication, 2013]. All these government initiatives and development plans aim to increase the country's competitiveness by moving to a more digital economy. Nevertheless, such plans also hinge on the access of the current and future workforce to digital tools., i.e., the first-order effects of the digital divide still play a crucial role in the BRICS context.

Notably, across all BRICS countries, computer connectivity at home is lower than internet connectivity at home. More than $60 \%$ of young students in BRICS countries are unconnected from the internet and do not have the opportunity to access the remote learning modalities. This situation raises substantial concerns for the future of those falling behind in their education, skills, and upcoming employment opportunities. As such, inequitable access to ICT in BRICS countries hampers progress and exacerbates the existing inequalities affecting groups even before the pandemic. Future growth in the BRICS countries depends on how well the youth are prepared to thrive in a digital economy. The evidence in the paper makes a strong case for improving digital access for the most vulnerable youth. The lack of access to digital tools will prevent the poorest youth from fully participating and competing in a digital economy.

Some BRICS countries fare better than others. For example, while India is well-known for being a global IT hub with an internationally requited workforce [Insights success, 2021; Lalwani, 2019], the connectivity of 15-24-year-olds through fixed internet and computers is shallow. Therefore, many young Indians from poorer and rural backgrounds lack the accessibility and skills to participate in the IT sector. Similarly, in South Africa, smaller shares of young people have access to the internet and computers at home. Demographically, both India and South Africa are young in terms of the shares of the working-age population. Therefore, it will be critical for their future economic growth to ensure all young people are prepared for a digitalized world instead of only the richest and urban young people.

More young people in Brazil, China, and Russia have access to the internet and computer at home. These countries in spite of relatively high overall economic inequality display lower economic inequality in access to the internet and a computer at home, suggesting that equitable access to these tools is possible, and this condition can be accelerated by the efficient policies. Furthermore, as accessibility increases in these countries, it will be essential to monitor secondorder effects, i.e., how often young people use digital tools. Some information on this is already available. For example, all three countries participate in Programme for International Student Assessment (PISA) which provides some insight into the use of ICT by 15-year old students. PISA 2018 data suggests that 15-year-old Brazilians and Russians spend more than 27 hours per week 
on the internet outside of school [OECD, 2021]. Moreover, linking students' reading performance with availability and use of digital skills, the report suggests that the digital divide goes far beyond the access, and the differences related to the 'how', 'when' and 'for what purpose a technology is used' also impact students' skills. The report also provides evidence that, on average, students' access to a computer linked to the internet at home for schoolwork is associated with the estimated percentage of correct reading items that focus on distinguishing facts from opinions in the PISA assessment. The implications of these findings are considerable for those BRICS countries that already have a high level of penetration of computers and the internet at home, highlighting a potential role of accelerating digital skills for education in detecting biased information.

\section{Policy Implications}

Economic contraction due to the COVID-19 pandemic raises concerns of de-prioritization of education globally [UNESCO, UNICEF, World Bank, 2020]. In the context of school closures, which is expected to increase learning loss and has shifted focus to increase digitalization of education systems, it is crucial to ensure adequate financing of education. Even before the pandemic, the expenditure on education as a share of GDP ranged from 3.8\% in India to $6.5 \%$ in South Africa [World Bank, 2020; UNICEF, 2018]. The new contexts introduced by COVID-19 are expected to increase strain on education financing more as countries move to digitalize their education system resulting in more costs. The survey of ministries of education carried out jointly by UNESCO, UNICEF, and the World Bank shows that "almost all participating countries required additional financial resources to cover COVID-19-related costs in the education sector", and BRICS countries were not the exception [UNESCO, UNICEF, World Bank, 2020] ${ }^{3}$. Furthermore, it is also known that "more countries expected cuts in 2020 than in 2021" [Ibid, p. 40], with low and lower-middle-income countries facing the strongest hardships ${ }^{4}$. However, potential reductions of education budgets could have dire and long-term implications on the economy of BRICS countries, given the share of the global youth population that they represent. Available evidence suggests that "investment funds in the education systems" in BRICS are vital in ensuring economic growth, and "there is a positive correlation between public expenditure on education and the value of GDP of the country" [Tomić, 2015, p. 19]. Furthermore, it is essential to ensure that the existing potential for economic growth should be provided by the equitable investment into education and training [Rodrigues, 2018, p. 85]. In other words, the most vulnerable should not be left behind by governmental policies. With that regard, the policies need to acknowledge that "people in rural areas continue to face greater challenges than people in urban areas in terms of remaining connected during the lockdown, especially in developing economies" [ITU, 2020, p. 2]. Therefore, expanding digital infrastructure with coverage of remote rural areas should be the key priority in BRICS countries. Although the return on these investments will not be immediate, the benefits of expanding the internet connectivity for the economy will go beyond education and employment.

\footnotetext{
3 The database with the country responses on the question 31 "Were additional financial resources required to ensure the response to COVID-19 for education?" is available publicly online on the website of all three organizations.

${ }^{4}$ No data are available on BRICS countries.
} 
At the international level, the importance of connecting students to the internet is evident in initiatives launched by international organizations. For example, UNICEF has launched the GIGA initiative, which seeks to connect all schools to the internet [UNICEF, 2021b]. Participation in such initiatives or launching a BRICS-centered initiative directed towards connecting students to the internet can help ensure disadvantaged students remain connected in these countries. As it is clear even after a year since the pandemic started that remote learning would play an important role in the delivery of education, disregarding the status of school operation, provision of the unconnected youth with the access to the internet should be prioritized. For BRICS countries with a lower prevalence of digital connectivity, the governments should invest more to ensure access to remote learning platforms through the landline or mobile networks. Alternatively, more costly measures include subsidizing the devices needed to access the internet and computers for learning.

Another area of potential cooperation for BRICS countries is knowledge sharing and peer learning in the development of digital infrastructure. For example, data costs in India are among the lowest. Improving first-order effects would require increasing the affordability of the internet. In Russia, the price of the internet is $\$ 0.11$ per MB. In China, it is $\$ 0.24$ per MB; in India, it is $\$ 0.34$ per MB and in South Africa is $\$ 1.23$ per MB [Broadband search, 2021]. Sharing information on lowering costs of the internet and increasing connectivity can particularly help India and South Africa. So far, BRICS ministries have focused on student mobility within BRICS countries, expanding the mandate of BRICS education ministries to include strategies to digitalize education systems, highlighting strategies to reduce the digital divide can help BRICS countries increase their digital competitiveness while achieving key SDGs.

Better understanding how countries can scale their digital infrastructure will be crucial. With overall access to the high-speed internet at home relatively high in Russia, China, and Brazil, these countries are closer to ensure equitable character of this access. India and South Africa have a long way to go to ensure expanded access to these tools at home while ensuring equity.

In terms of learning losses and access to education during school closure, the evidence in the paper makes a strong case for re-opening educational institutions. Being the most vulnerable, the poorest and/or rural young students in BRICS are highly prone to the risk of being left behind and bear the worst consequences of the disrupted in-person classroom instruction. However, COVID-19-caused school closures also provide BRICS countries with an opportunity to rethink their digital economy strategy, refocusing discussions on digital infrastructure. Already BRICS countries have acknowledged that the consequences of the COVID-19 pandemic for developing education potential have been large and include the need to rethink the education paradigm [BRICS, 2020]. In this process, it will be important to build a system where the most vulnerable student youth can access and use digital tools, opening a world of learning and potential for them. 


\section{References}

Avanesian G., Mizunoya S., Amaro D. (2021) How Many Students Could Continue Learning during COVID-19-caused School Closures? Introducing a new reachability indicator for measuring equity of remote learning. International Journal of Educational Development, 84, 102421.

Azevedo J.P., Hasan A., Goldemberg D., Geven K., Iqbal S.A. (2020) Simulating the Potential Impacts of COVID-19 School Closures on Schooling and Learning Outcomes: A Set of Global Estimates. Policy Research Working Paper, 36, 1, pp. 1-58. Doi:10.1093/wbro/lkab003

Baller S., Dutta S., Bruno L. (2016) The Global Information Technology Report 2016. Geneva: World Economic Forum. Retrieved from: https://www.weforum.org/reports/the-global-information-technologyreport-2016/

Bonfadelli H. (2002) The Internet and Knowledge Gaps: A Theoretical and Empirical Investigation. European Journal of Communication, 17, 1, pp. 65-84.

BRICS (2020) Declaration of the $7^{\text {th }}$ Meeting of BRICS Ministers of Education. BRICS.

Brotcorne P., Damhuis L., Laurent, V., Valenduc G. et Vendramin P. (2010) Diversité et vulnérabilité dans les usages des TIC - La fracture numérique au second degré (Diversity and vulnerability in ICT usageThe second order digital divide. Gent: Academia Press.

Deng I., Shen X. (2021) China's 'Two Sessions' 2021: Plans for 'Digital China' Transformation Come with Increased Regulations for Personal Data. Retrieved 06 09, 2021, from South China Morning Posts: https://www.scmp.com/tech/big-tech/article/3124305/chinas-two-sessions-2021-plans-digital-chinatransformation-come

Department of Communication (DOC) (2013) South Africa Connect: Creating Opportunities, Ensuring Inclusion. Government Gazette (37119), pp. 4-63.

Digital India (n.d.). Retrieved 06.09.2021. Available at: https://www.digitalindia.gov.in/

Erreygers G., Van Ourti T. (2011) Measuring Socioeconomic Inequality in Health, Health Care and Health Financing by Means of Rank-dependent Indices: A Recipe for Good Practice. Journal of Health Economics, 30, 4, 685-694.

Hanushek E., Woessmann L. (2020) Education, Knowledge Capital, and Economic Growth. The Economics of Education, pp. 171-182.

How do U.S. Internet Costs Compare to the Rest of the World? (n.d.). Retrieved 06.09.2021, from Broadband Search: https://www.broadbandsearch.net/blog/internet-costs-compared-worldwide Ignatov A. (2020) The Digital Economy of BRICS: Prospects for Multilateral Cooperation. International Organisations Research Journal, 15, 1, pp. 31-62.

Illsley R., Le Grand J. (1987) The Measurement of Inequality in Health. Health and Economics. British Association for the Advancement of Science (ed. A. Williams). London: Palgrave Macmillan, pp. 12-36.

India: The Fastest Growing Tech Hub in the World. (n.d.). Retrieved 06.09.2021, from Insights success:

https://www.insightssuccess.in/india-the-fastest-growing-tech-hub-in-the-world/

ITU (2014) Digital Opportunities: Innovative ICT Solutions for Youth Employment. Geneva.

ITU (2020) Measuring Digital Development. Facts and Figures. Geneva.

Kakwani N.C. (1977) Measurement of Tax Progressivity: An International Comparison. The Economic Journal, 87(345), pp. 71-80.

Kakwani N., Wagstaff A., van Doorslaer E. (1977) Socioeconomic Inequalities in Health: Measurement, Computation, and Statistical Inference. Econometrics, 77, pp. 87-103.

Lalwani A. (2019) This Is How India Can Become the Next Silicon Valley. Retrieved 06.09.2021, from World Economic Forum: https://www.weforum.org/agenda/2019/10/india-technology-developmentsilicon-valley/ 
Larionova M. (2020) Role of BRICS in the Global Economy. Retrieved 06.09.2021, from BRICS Information Portal: http://infobrics.org/post/31036/

Livingstone S., Bober M., Helsper E. (2005) Inequalities and the Digital Divide in Children and Young People's Internet Use: Findings from the UK Children Go Online Project. Monograph. London: London School of Economics and Political Science.

Niemczyk E.K., de Beer L., J., S. H. (2021) The Challenges Posed by COVID-19 to the BRICS Education Systems: Lessons to be Learnt. Perspectives in Education, pp. 173-188.

OECD (2018) Digital Government Review of Brazil: Towards the Digital Transformation of the Public Sector. OECD Digital Government Studies. Paris: OECD Publishing. Publishing.

OECD (2021) 21st-Century Readers: Developing Literacy Skills in a Digital World. PISA. Paris: OECD

Plat D. (2021) IC2: Inequality and Concentration Indices and Curves (R package version 1.0-1). Retrieved from: https://CRAN.R-project.org/package=IC2

Purushothaman A., Dirckinck-Holmfeld L., Kuruvilla M. (2017) Second Order Divide in Internet Usage in Developing Countries: An Overlooked Issue? International Journal of Digital Literacy and Digital Competence, pp. 1-13.

Ragnedda M., Ruiu M. (2020) Digital Capital. A Bourdieusian Perspective on the Digital Divide. Emerald Publishing.

Regidor E. (2004) Measures of Health Inequalities: Part 2. Journal of Epidemiology and Community Health, 58, 11, pp. 900-903.

Rodrigues J. (2018) BRIC's Education Challenge to Economic Development. Journal of Education \& Social Policy, 5, 3, pp. 85-89.

The World Bank (2020) Government Expenditure on Education, Total (\% of GDP) - Brazil, Russian Federation, India, China, South Africa, High income. Retrieved 06.09.2021, from The World Bank: https://data.worldbank.org/indicator/SE.XPD.TOTL.GD.ZS?locations=BR-RU-IN-CN-ZA-XD

The World Bank (2021) Share of Youth Not in Education, Employment or Training, Total (\% of youth population) - Brazil, Russian Federation, India, China, South Africa. Retrieved 06.09.2021, from https://data.worldbank.org/indicator/SL.UEM.NEET.ZS?locations=BR-RU-IN-CN-ZA

Tomić Z. (2015) Analysis of the Impact of Public Education Expenditure on Economic Growth of European Union and BRICS. Economic Analysis, 48, (1-2), pp. 19-38.

Tsaurai K., Chimbo B. (2020) Technology, Poverty, and Education within the BRICS'Context. International Journal of Economics \& Business Administration (IJEBA), 8, 4, pp. 471-487.

UNESCO (2014) BRICS Building Education for the Future. Paris, France.

UNESCO, UNICEF, The World Bank (2020) What Have We Learnt? Overview of findings from a survey of ministries of education on national responses to COVID-19.

UNICEF (2018) Figure 8.26 Government Expenditure on Education and its Percentage of GDP, 1992-2017 Chapter 8: Education and Child Development. Retrieved 06.09. 2021, from UNICEF: https://www.unicef.cn/ en/figure-826-government-expenditure-education-and-its-percentage-gdp-19922017

UNICEF (2020) COVID-19: Are Children Able to Continue Learning during School Closures. A Global Analysis of the Potential reach of Remote Learning Polices Using Data from 100 countries.

UNICEF (2021, March) COVID-19 and School Closures: One Year of Education Disruption. Retrieved from UNICEF DATA: https://data.unicef.org/resources/one-year-of-covid-19-and-school-closures/ UNICEF (2021) Giga. Connecting Every School to the Internet. Retrieved 06.09.2021, from UNICEF: https://www.unicef.org/innovation/giga

Van Deursen A., van Dijk J. (2019) The First-level Digital Divide Shifts from Inequalities in Physical Access to Inequalities in Material Access. New Media \& Society, pp. 354-375.

Van Doorslaer E., Wagstaff A., Bleichrodt H., Calonge S., Gerdtham U., Gerfin M., Winkelhake O. (1977) Income-related Inequalities in Health: Some International Comparisons. Journal of Health Economics, 16, 1, pp. 93-112. 
Wagstaff A., van Doorslaer E. (1994) Measuring Inequalities in Health in the Presence of Multiple-category Morbidity Indicators. Health Economics, 3, 4, pp. 281-291.

Wagstaff A., Paci P., van Doorslaer E. (1991) On the Measurement of Inequalities in Health. Social Science \& Medicine, 33, 5, pp. 545-557.

Yitzhaki S., Slemrod J. (1987) Welfare Dominance: An Application to Commodity Taxation. The American Economic Review, pp. 480-496.

\section{Data sources}

1. Brazil Continuous National Household Sample Survey (Continuous PNAD) - 2018-2019, https://www.ibge.gov.br/en/statistics/social/population/20620-summary-of-indicators-pnad2.html?=\&t=oque-e

2. China Health and Retirement Longitudinal Study 2018, http://charls.pku.edu.cn/index/en.html

3. India Demographic and Health Survey - 2015-2016, https://dhsprogram.com/methodology/ survey/survey-display-355.cfm

4. South Africa General Household Survey - 2019, http://www.statssa.gov.za/publications/ P0318/P03182019.pdf

5. The Russia Longitudinal Monitoring Survey - Higher School of Economics (RLMS-HSE) - 2019, https://www.hse.ru/en/rlms/

\section{Funding}

This research was financially supported by the Southern Federal University, 2021, 07/2020-02-AP. 